\title{
Natural History of Refsum's Syndrome in a Gloucestershire Family
}

\author{
A. M. G. CAMPBELL, $*$ D.M., F.R.C.P. ; E. R. WILLIAMS, $\dagger$ M.A., M.B., M.R.C.P.
}

Brit. med. F., 1967, 3, 777-779

Thirty-nine cases of Refsum's syndrome (Refsum, 1946) or heredopathia atactica polyneuritiformis have now been reported (Carrell et al., 1966). The neurological features-namely, a mixed sensory and motor peripheral neuropathy, atypical retinitis pigmentosa with night blindness and constricted visual fields, cerebellar ataxia, and nerve deafness-are well attested and have been recently reviewed (Alexander, 1966), while abnormalities occurring outside the central nervous system include ichthyosis, epiphysial dysplasia, and cardiomyopathy (Gordon and Hudson, 1959). The disease is inherited as an autosomal recessive (Refsum, 1946) and most cases have occurred in consanguineous families.

The discovery of an excess of phytanic acid $(3,7,11,15$-tetramethylhexadecanoic acid) in the serum and tissue lipids of these patients (Klenk and Kahlke, 1963 ; Eldjarn, 1965) has opened several exciting fields of speculation regarding the natural history of this disease, the aetiology of which is now partly understood. This has led us to investigate further a family living in the Forest of Dean area of Gloucestershire. Two members of this family have Refsum's syndrome and have been followed by one of us (A. M. G. C.) since 1958 and 1960 respectively.

We wish to report the results of a clinical and biochemical survey of three generations of the family, to record abnormalities in phytanic acid content of the cerebrospinal fluid (C.S.F.) in one of the patients, and to comment on the marked fluctuation in the clinical course of the disease, which was paralleled by variations in levels of C.S.F. protein.

\section{Case 1}

The patient, a man now aged 28, was first seen in 1958 at the age of 19, complaining of weakness of the limbs and unsteadiness and difficulty in walking, which had become worse after a febrile illness.

Since the age of 7 he had been noticed to be unsteady and had never been able to play games at school. At 14 he saw an orthopaedic surgeon because of pes cavus, and his mother stated that his feet had been deformed' since he started to walk; at this time he first noticed deafness. In September 1957 he had "Asian" influenza and a fortnight later developed weakness, numbness, and tingling of the limbs and slurred speech. He was admitted to a near-by hospital and was first thought to have an infective polyneuritis, as the C.S.F. protein was over $300 \mathrm{mg} . / 100 \mathrm{ml}$.

When first seen he was found to have a severe peripheral neuropathy with absent reflexes, marked wasting of the hands and lower legs, and a glove-and-stocking anaesthesia to all sensory modalities. He also had bilateral nerve deafness, ataxia and intention tremor, clawing of the feet, and atypical retinitis pigmentosa (Fig. 1) with some degree of optic atrophy. The pupils were small, but reacted to light and accommodation. The visual acuity was $6 / 9 R$ and $6 / 6 \mathrm{~L}$ and there was a generalized constriction of the visual fields.

The patient has been followed over the past eight years and his disease has taken a variable downhill course. Over this period he has been extensively investigated; haemoglobin, white blood count, erythrocyte sedimentation rate, serum electrolytes and urea, fat balance, xylose excretion, electroencephalogram, urinary porphyrins and amino-acids, urinary ketosteroid excretion, and skull and chest

* Neurologist, Bristol Royal Infirmary.

t Late Medical Registrar, United Bristol Hospitals. Present appointment: Senior. Medical Registrar, Bath United Hospital. radiographs had all been normal. The serum cholesterol was 150 mg./100 ml., serum lipids were $0.71 \mathrm{~g} . / 100 \mathrm{ml}$., and serum $\alpha_{2-}$ globulin just increased at $0.9 \mathrm{~g} . / 100 \mathrm{ml}$. (liver-function tests were otherwise normal). The electrocardiogram was normal in 1958, but by 1966 there were flat $T$ waves over the lateral chest leads. Foot radiographs (Fig. 2) showed metatarsal dysplasia with an equinovarus deformity and shortening of all the metatarsals except the second. Electromyography revealed only changes associated with a reduced muscle mass, and muscle biopsies showed fibrosis. The C.S.F. was at normal pressure with no increase in cells, and was

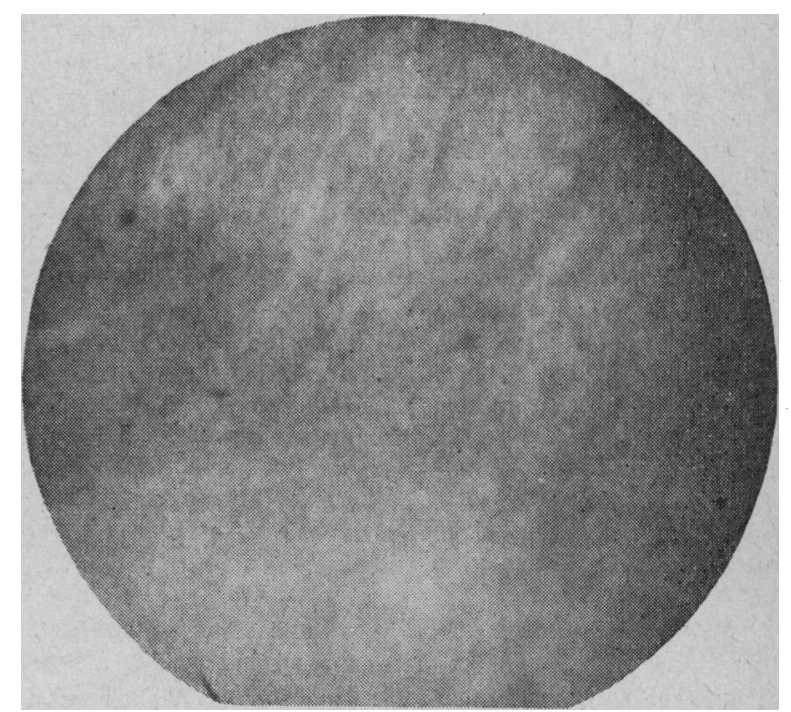

Fig. 1.-Case 1. Fundus photograph showing atypical retinitis pigmentosa.

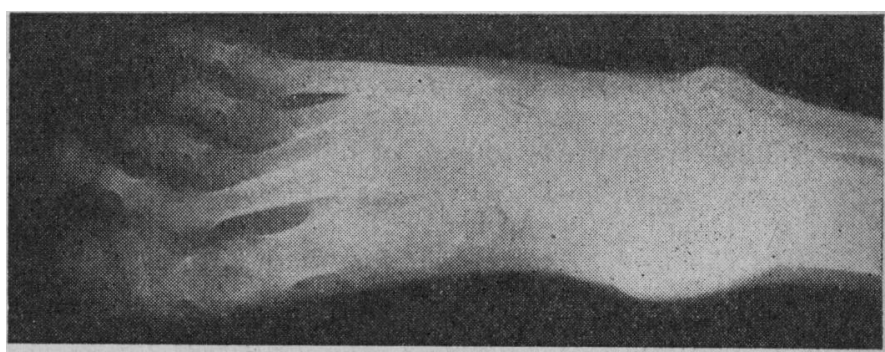

FIG. 2.-Case 1. Radiograph of foot.

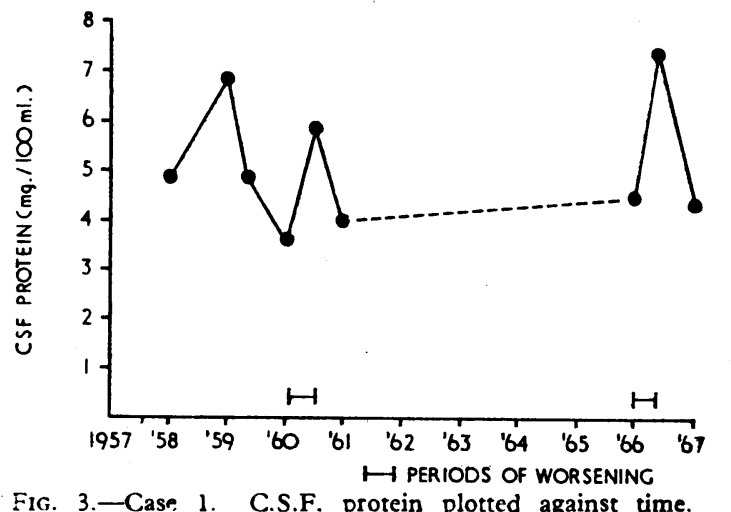


a pale yellow; the protein was consistently greatly raised, ranging from 368 to $732 \mathrm{mg} . / 100 \mathrm{ml}$. A great excess of globulin was present. It seemed possible that exacerbations of the disease were associated with a rise in C.S.F. protein (Fig. 3).

Between February and August 1966 he worsened steadily and became unable to walk at all in spite of being on a low phytol diet, but between October 1966 and February 1967 there was a great improvement, particularly in motor power peripherally, so that he was able once more to write and type, and could walk without assistance and control his invalid motor vehicle. During this period the only dietary reduction imposed was the avoidance of green vegetables and fat meat.

\section{Case 2}

A married sister, aged 33, of the previous patient had a healthy childhood and adolescence, though mild deformity of the feet was noted by her mother. At the age of 20 she developed an acute weakness of the limbs and unsteadiness, again following a febrile illness. She was thought to have poliomyelitis and was admitted to hospital, where she was found to have weakness of the right arm and both legs, absent tendon jerks, ataxia of all limbs, and impaired vibration sense in the legs. A diagnosis of infective polyneuritis was again made, supported by a C.S.F. protein level of $400 \mathrm{mg} . /$ $100 \mathrm{ml}$. She slowly improved; at the age of 22 she married and has two daughters, aged 6 and 8 . During both pregnancies she thought she was noticeably weaker and more ataxic. In 1963, when aged 30 , she had a total hysterectomy for menorrhagia with conservation of the right ovary. After this she again became weak and unsteady but improved in a few months, and since 1964 has remained well able to cope with her household duties, and feels that she has steadily improved. Neither this patient nor her brother has shown any mental deterioration.

When examined in 1966 she was a good deal better than when we saw her in 1960 . She had bilateral cerebellar signs, bilateral drop-foot with absent ankle jerks and mild wasting of the hand and foot muscles, and claw-feet similar to her brother's, with the same atypical retinitis and nerve deafness. The C.S.F. protein had dropped to $83 \mathrm{mg} . / 100 \mathrm{ml}$, radiographs of the tarsal bones were normal, and her disease was clearly not so severe as that of her brother.

\section{Family Study}

The family tree of the three generations studied is given in Fig. 4. The family are of yeoman stock and live in a small Gloucestershire town. There is no history of any other familial disease and no suggestion of consanguinity; while I 1 traces his ancestry back through four generations of Forest of Dean dwellers, I 2 is a native of Cheltenham. There is no consanguinity in any of the spouses of the sibs of the propositi.

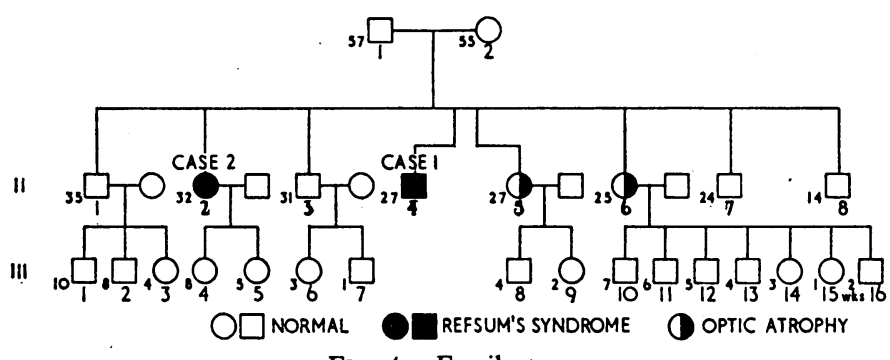

FIg. 4.-Family tree.

All the subjects shown in the family tree were examined. Two sisters (II 5 and 6 ) were found to have a mild optic atrophy and II 6 had a retinal cyst. No abnormality was found in any others, and in particular none of the third generation had retinitis pigmentosa, ataxia, or clinical evidence of bone disorder.

Serum from everyone in the family was examined for the presence of phytanic acid, but with the exception of the propositi this was absent in all of them. Creatine phosphokinase activity and serum caeruloplasmin levels were also estimated in the propositi and eight relatives (see Table). It can be seen that the creatine phosphokinase is raised in both the propositi, as might be expected in any wasting disease (Gubbay et al., 1966). The serum caeruloplasmin was raised in Case 1 and also in his younger sister (II 6), who had optic atrophy, though not in his twin sister.

\begin{tabular}{|c|c|c|c|c|}
\hline \multicolumn{5}{|c|}{ Biochemical Findings } \\
\hline & Age & $\begin{array}{c}\text { Phytanic Acid } \\
\text { (\% of Total } \\
\text { Fatty Acid) }\end{array}$ & $\begin{array}{c}\text { Creatine } \\
\text { Kinase } \\
\text { (i.u.) }\end{array}$ & $\begin{array}{c}\text { Caerolo- } \\
\text { plasmin } \\
\text { (mg./100 ml.) }\end{array}$ \\
\hline 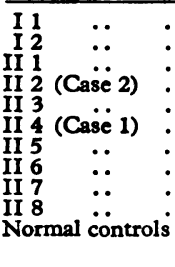 & $\begin{array}{l}57 \\
55 \\
35 \\
32 \\
31 \\
27 \\
27 \\
25 \\
24 \\
14\end{array}$ & $\begin{array}{c}0 \\
0 \\
0 \\
15 \cdot 6 \\
0 \\
34 \cdot 7 \\
0 \\
0 \\
0 \\
0 \\
0\end{array}$ & $\begin{array}{c}11 \\
16 \\
20 \\
90 \\
15 \\
68 \\
13 \\
8 \\
18 \\
56 \\
\text { Males up to } 66 \\
\text { Females up to } 43\end{array}$ & $\begin{array}{r}5 \cdot 3 \\
13.1 \\
10 \cdot 6 \\
18.9 \\
10.5 \\
26 \cdot 0 \\
8 \cdot 8 \\
32.8 \\
5.0 \\
10.6 \\
14.25\end{array}$ \\
\hline
\end{tabular}

\section{Phytanic Acid}

The propositus (Case 1) was shown to have a very high level of phytanic acid in the serum. This was estimated by gasliquid chromatography in Oslo (Eldjarn, personal communication, 1966) to be $90 \mathrm{mg} . / 100 \mathrm{ml}$. of serum, a value among the highest so far found in this condition by these workers. An aliquot of the same sample was found to contain phytanic acid in a concentration of $34.7 \%$ of total serum fatty acids by Professor J. N. Cumings. A sample of serum taken in 1960 and freeze-dried contained $12 \%$ of the total fatty acids as phytanic acid.

In Case 2 the serum contained $15.6 \%$ of the total of fatty acids as phytanic acid (July 1966) and $14.3 \%$ when re-estimated in February 1967.

C.S.F. samples from both propositi were also examined. A freeze-dried specimen taken from Case 1 in 1960 contained phytanic acid in a concentration of $10 \%$ of total fatty acids. A specimen taken in August 1966, when the disease had progressed considerably, contained $19.4 \%$. No phytanic acid was demonstrated in the C.S.F. in Case 2, however. These 1966 C.S.F. specimens were also subjected to phospholipid estimation and protein electrophoresis and showed markedly raised total phospholipid, lecithin, and globulin values.

\section{Discussion}

The elevated phytanic acid levels here reported are in accordance with previous studies (Kahlke, 1964 ; Eldjarn, 1965 ; Rake and Saunders, 1966), and it now seems established that the clinical features of the disease are associated with an impairment of oxidative degradation of this branched-chain fatty acid (Eldjarn et al., 1966). Though an excess of phytanic acid has been found in many tissues, including liver, kidney, brain, nerve, skeletal muscle, and urine (reviewed by Rake and Saunders, 1966), C.S.F. levels have not previously been recorded.

The family study shows that the inheritance demonstrated is compatible with an autosomal recessive mode of transmission. Kahlke and Richterich (1965) found higher amounts of phytanic acid in the serum of the apparently healthy mother of a patient with Refsum's syndrome than the serum of the patient ; this raises the possibility of a biochemical abnormality being demonstrable in heterozygous carriers of the disease, a situation akin to that in thalassaemia or in glucose-6-phosphatase deficiency-Von Gierke's disease (Cori and Cori, 1952). This would be of importance in genetic counselling, but we found no phytanic acid in the serum of any relatives, confirming the 
findings in the parents of two Norwegian cases of Refsum's syndrome (Eldjarn, personal communication, 1966).

The remarkable variability of the clinical course of Refsum's syndrome is now well known. Of Refsum's original cases, one presented after an acute febrile illness, and one apparently began as a sequel to the physical exertion of fishing near the Lofoten Islands. In both cases the worsening immediately after a febrile episode had led to their first hospital admission. Another of Refsum's cases relapsed regularly in the springtime ; in the light of our present knowledge it is tempting to speculate that this might have been associated with seasonal dietary variations. A member of one of Refsum's original families has recently been reported to have improved after longterm mental hospital admission, possibly again associated with low vegetable intake (Eldjarn et al., 1966). Following preliminary reports on the value of a diet low in phytanic acid Eldjarn et al., 1966) in the condition, this diet was given to our Case 1, but without improvement. Because of the patient's intolerance the diet was relaxed, and on moderate restriction he was at the time of writing showing steady improvement.

A fluctuation in C.S.F. protein was evident in our cases, and reference to Fig. 3 might suggest that there was a relation between the activity of the disease and the C.S.F. protein in Case 1 over the nine-year period of study. The C.S.F. protein in Case 2 has dropped from $400 \mathrm{mg} . / 100 \mathrm{ml}$. in 1958 to 83 $\mathrm{mg} . / 100 \mathrm{ml}$. in 1966 . Since 1964 , a year after her hysterectomy, she has improved markedly and steadily. This is of interest as it might indicate that an alteration in hormone balance after hysterectomy may have favourably influenced the course of the disease.

The only biochemical abnormality consistently described so far in Refsum's syndrome is that of phytanic acid accumulation. While the C.S.F. phospholipid, lecithin, and globulin increases here recorded may simply reflect this abnormality, abnormalities of copper metabolism in the condition have been reported by several workers (Richterich et al., 1965 ; Rake and Saunders, 1966). In Case 1 and a sib with optic atrophy (II 6) the caeruloplasmin was raised (see Table). The significance of this finding is at present obscure.
Continued follow-up of patients with Refsum's syndrome, with phytanic acid estimations being compared to clinical state, would seem a fruitful field for study. While alteration in phytanic acid intake may well affect the disease process, there may be physiological factors influencing the metabolic pathways of phytanic acid breakdown which also affect the course of the disease. Such a hypothesis would fit the observations above regarding the effect of intercurrent illness and improvement in a woman after the child-bearing period.

\section{Summary}

The results are reported of a clinical and biochemical study of two sibs with Refsum's syndrome who have been studied over a period of nine years. Three generations of the family were investigated, and no significant evidence of biochemical abnormality was found in any of the unaffected members. The serum phytanic acid level was raised in both patients, and high levels of phytanic acid in cerebrospinal fluid were present in one.

Fluctuations in the severity of the condition are compared with C.S.F. protein levels, and possible explanations for this characteristic variation discussed.

\section{REFERENCES}

Alexander, W. S. (1966). f. Neurol. Neurosurg. Psychiat., 29, 412. Carrell, R. W., Scott, P. J., and McLellan, G. H. (1966). N.Z. med. \}., $65,766$.

Cori, G. T. T., and Cori, C. F. (1952). F. biol. Chem., 199, 661.

Eldjarn, L.' (1965). Scand. F. clin. Lab. Invest., 17, 178.

Eldjarn, L. (1965). Scand. F. clin.

Gordon, N., and Hudson, R. E. B. (1959). Brain, 82, 41.

Gubbay, S. S., Walton, J. N., and Pearce, G. W. (1966). F. Neurol. Neurosurg. Psychiat., 29, 500.

Kahlke, W. (1964). Klin. W'schr., 42, 1011

C and Richterich, R. (1965). Amer. F. Med., 39, 237.

Klenk, E., and Kablke, W. (1963). Hoppe-Seylers Z. physiol. Chem., 333, 133.

Rake, M., and Saunders, M. (1966). F. Neurol. Neurosurg. Psychiat., 29, 417.

Refsum, S. (1946). Acta psychiat. scand., Suppl. No. 38, p. 9. Richterich, R., van Mechelen, P., and Rossi, E. (1965). Amer. F. Med.,
39.

Brit. med. F., 1967, 3, 779-780

Respiratory failure in patients with chronic bronchitis and emphysema is usually part of a generalized cerebral depression from hypoxia and hypercapnia. It may come on suddenly, however, as a result of bronchial blockage from phugs of inspissated secretions (Simpson, 1962). In the following case a generalized peritonitis induced acute respiratory failure in a severely emphysematous patient.

\section{CASE Report}

A man aged 48 was admitted to hospital with bronchopneumonia and congestive cardiac failure complicating his long-standing chronic bronchitis and emphysema. His blood gases at the time of this admission were: $p H 7.35$ units, $\mathrm{PCO}_{2} 72.5 \mathrm{~mm}$. $\mathrm{Hg}$, base excess $+8 \mathrm{mEq} / 1$., standard bicarbonate $31 \mathrm{mEq} / 1$., and $\mathrm{PO}_{2} 79 \mathrm{~mm} \mathrm{Hg}$. Chest $x$-ray examination showed appreciable generalized emphysema with bullous formation affecting both left and right apical zones

together with recent inflammatory shadowing at the left base. After a period of bed rest associated with diuretics, digoxin, and antibiotic therapy, he made a satisfactory recovery but was still considerably disabled by his emphysema. His blood gases on 19 April 1966that is, the day before his discharge-showed an established ventilatory insufficiency as well as impaired alveolar-arterial gas exchange (see Table).

He was advised to stop smoking, as this was considered the only thing likely to delay progression of his emphysema.

On 6 May at 4.15 p.m. he was reaumitted in acute respiratory failure with complete apnoea. Emergency treatment in the casualty department consisted of endotracheal intubation with positivepressure oxygen respiration, intravenous infusion of $7.5 \%$ bicarbonate, and hydrocortisone also administered by the intravenous route. The $\mathrm{pH}$ on admission was 7 . Treatment was continued in the intensive care unit, where the patient was put on an EastRadcliffe respirator. Two hours later his general condition improved and he regained consciousness. By this time he had received 1 litre of $7.5 \%$ bicarbonate and was on tetracycline $100 \mathrm{mg}$. intramuscularly six-hourly. Investigations produced the following results: P.C.V. $60 \%$; Hb $128 \%$; serum electrolytes- $\mathrm{Na} 137$ $\mathrm{mEq} / 1$., K $4.7 \mathrm{mEq} / 1$., $\mathrm{Cl} 81 \mathrm{mEq} / 1$. ; blood urea $83 \mathrm{mg} . / 100 \mathrm{ml}$. The blood gases at 6.30 p.m. are shown in the Table.

He now complained of severe abdominal pain and was found to have a rigid and silent abdomen. A previous long-standing history 